\title{
A preliminary outcome of modified enhanced recovery protocol versus standard of care in radical cystectomy: an Indonesian experience
}

\author{
Ahmad Zulfan Hendri ${ }^{1}$, Said Alfin Khalilullah ${ }^{2 *}$ and Gede Andi Aditya ${ }^{2}$
}

\begin{abstract}
Background: This study aimed to evaluate the outcomes of modified Enhanced Recovery After Surgery (ERAS) protocol and standard of care (SC) in bladder cancer patients who underwent radical cystectomy (RC). The length of stay and complications rates were the primary outcomes. Time functional recovery, bowel movement, mobilization, drain removal, and other perioperative outcomes were the secondary outcomes.
\end{abstract}

Methods: A cohort retrospective study was conducted to investigate the effectiveness of the modified ERAS protocol compared to SC in 61 patients who underwent RC (36 ERAS vs. 25 SC).

Results: The modified ERAS protocol was associated with shorter length of stay ( $9.3 \pm 5.0$ days vs. $12.6 \pm 6.7$ days, $P=0.032)$ and reduction in important postoperative milestones, including days to first solid diet (3.5 $\pm 1.6 \mathrm{vs} .5 .5 \pm 1.5$, $P=0.000$ ), days to first defecation ( $4.8 \pm 2.4$ vs. 7.2 $\pm 2.4, P=0.001$ ), days to first walking (4.7 \pm 2.2 vs. $7.9 \pm 2.4$,

$P=0.000)$, and days to drain removal ( $3.9 \pm 1.3$ vs. $5.9 \pm 2.5 P=0.001)$. Postoperative complications rates were lower in the modified ERAS groups, but the result was not statistically significant $(P=0.282)$. Also, there were no significant differences between transfusion requiring, intensive care monitoring, re-operation, and re-admission between groups.

Conclusion: This study demonstrated that the modified ERAS protocol for RC can accelerate postoperative recovery without any adverse effects on morbidity and mortality.

Keywords: Radical cystectomy, Modified ERAS, Bladder cancer, Complication

\section{Background}

Currently, there has been a shift in perioperative management from the previous standard of perioperative care which included preoperative fasting routines, various forms of bowel preparation, postoperative bowel rest, and gastrointestinal decompression [1]. The new standard of care (SC) is now developing into a clinical pathway

\footnotetext{
*Correspondence: saidalfink@gmail.com

${ }^{2}$ Division of Urology, Department of Surgery, Dr. Sardjito General

Hospital, Universitas Gadjah Mada, Yogyakarta, Indonesia

Full list of author information is available at the end of the article
}

known as the Enhanced Recovery After Surgery (ERAS) protocols [2-5].

First initiated in 1990 by Professor Henrik Kehlet, ERAS or "fast-tract" programs have become an important focus in perioperative management after colorectal surgery, thoracic and vascular surgery, and now radical cystectomy (RC) [6]. The key importance of the ERAS protocol is preoperative counseling, preoperative nutrition, avoidance of perioperative fasting and carbohydrate loading for up to $2 \mathrm{~h}$ preoperatively, standardized analgesic regimens (epidural and non-opioid) and anesthesia, and early mobilization [3]. Emphasizing that the current health-care system is based on cost reduction and the 
transparency of surgical outcomes, the ERAS protocols have tremendous clinical values and important implication for health systems in general $[2,4]$.

The ERAS protocols, which are multimodal perioperative care pathways, are designed to modify the body's response to stress in major surgery by minimizing complications and length of stay (LoS) [3], improving cardiopulmonary function, achieving faster restoration of bowel function, and obtaining rapid recovery for normal activities [4]. Multidisciplinary teams must work together through the perioperative period to shorten the process and optimize the patient care [3]. Studies have shown that ERAS protocols could reduce LoS, postoperative complications, and decrease re-admission rate [5].

Several studies have published the application of ERAS in urological surgery and shown a good result [7-10]. However, implementing the ERAS protocol remains a clinical problem. Accordingly, we tried to make its application simpler with a modified ERAS protocol. In this study, we evaluated the effectiveness of the modified ERAS protocol versus the traditional SC. We hypothesized the analysis would show the modified ERAS can accelerate postoperative recovery.

\section{Methods}

\subsection{Data collection}

A cohort retrospective study was conducted at the Urology Department, Dr. Sardjito General Hospital, in
Indonesia to compare outcomes of the modified ERAS with SC in 61 patients who underwent RC (36 modified ERAS vs. 25 SC) between January 2014 and June 2020. This study was approved by the Ethics Committee. All the data came from patients' medical records. All patients similar in terms of operative procedure and type of urinary diversion were performed by a single operator.

\subsection{The modified ERAS protocol}

We are not full applying all of the elements of ERAS protocols in our center because no standardized multidisciplinary agreement has yet been reached there, regarding the implementation of the full ERAS protocols. The modified ERAS protocol is described in Table 1. The main differences between the standard and modified ERAS protocols are in the administration of low molecular weight heparin for thrombosis prophylaxis, carbohydrate loading before surgery, multimodal analgesia, early postoperative oral intake, and use of perianastomotic and pelvic drainage (Table 2).

\subsection{Statistical analysis}

All data analyses were performed using the SPSS 23.00 (IBM Corp., Chicago). Shapiro-Wilk tests were used to analyze the normality of data. When data distribution was skewed, we analyzed the data using a nonparametric test. Differences in baseline or final data between two groups were analyzed using an independent t-test

Table 1 Modified ERAS protocol

\begin{tabular}{|c|c|}
\hline Item & Component \\
\hline \multirow[t]{5}{*}{ Preoperative } & Stop smoking since deciding to do the surgery \\
\hline & No bowel preparation until planned for colon involvement \\
\hline & Diet: fasting $6 \mathrm{~h}$ before surgery (according to anesthesia), carbohydrate loading $4 \mathrm{~h}$ before surgery (water with glucose 400 mg) \\
\hline & Prophylactic antibiotic (cephalosporin 2nd or cefazolin) \\
\hline & Consultation with hemato-oncology division for the evaluation of LMWH heparin for the prevention of DVT \\
\hline \multirow[t]{4}{*}{ Intraoperative } & Prevention of hypothermia \\
\hline & Use of multimodal analgesia \\
\hline & Goal directed intraoperative fluid therapy \\
\hline & NGT is removed immediately after surgery \\
\hline \multirow[t]{9}{*}{ Postoperative } & Avoid the use of opioid, instead of using paracetamol and NSAIDS \\
\hline & Postoperative oral intake as early as possible. If tolerance is good, fluid diet can be started $12 \mathrm{~h}$ after surgery \\
\hline & Chew gum for 15 min 3 times a day on delayed intake patients \\
\hline & Administration of alinamin F, if needed, to stimulate intestinal motility \\
\hline & $\begin{array}{l}\text { If the patient is unable to take diet after 3-4 days, but bowel activity is present, consider diet through NGT. If there is no bowel } \\
\text { activity, begin total parenteral nutrition }\end{array}$ \\
\hline & Postoperative gradual mobilization (since H-0 start to sitting) \\
\hline & Intravenous fluid restriction. Oral fluid intake is more preferred \\
\hline & Giving gastrointestinal prophylaxis with ranitidine until bowel function returns to normal \\
\hline & Administration of anti-emetic, Metoclopramide if needed \\
\hline
\end{tabular}


Table 2 Difference between ERAS and modified ERAS

\begin{tabular}{|c|c|c|}
\hline Item & ERAS & Modified ERAS \\
\hline Preoperative fasting & Carbohydrate loading $2 \mathrm{~h}$ before surgery & $\begin{array}{l}\text { Fasting } 6 \text { h before surgery (according to anesthesia), carbo- } \\
\text { hydrate loading } 4 \text { h before surgery (water with glucose } \\
400 \text { mg or clear juice like apples juice) }\end{array}$ \\
\hline Thrombosis prophylaxis & Heparin 5000u given before incision & $\begin{array}{l}\text { Consultation with hemato-oncology division for the evalu- } \\
\text { ation of LMWH heparin for the prevention of DVT }\end{array}$ \\
\hline Analgesia & $\begin{array}{l}\text { Goal is to avoid IV opioids. Postoperative analgesia includ- } \\
\text { ing thoracic epidural analgesia }\end{array}$ & $\begin{array}{l}\text { NSAID intravenous analgesia postoperative such as } \\
\text { ketorolac for } 3 \text { days and continue with oral paracetamol } \\
500 \text { mg every } 6 \text { to } 8 \mathrm{~h}\end{array}$ \\
\hline Postoperative diet & Oral nutrition started $4 \mathrm{~h}$ after surgery & Oral intake can be started $12 \mathrm{~h}$ after surgery \\
\hline Preventing PONV & Multimodal PONV prophylaxis in all patients & Give metoclopramide if needed \\
\hline pelvic drainage & Omission of the use of perianastomotic and/or pelvic drain & Use of perianastomotic and pelvic drainage \\
\hline Minimally invasive approach & Use of laparoscopic/robotic technique & We still using open surgery in several cases, \\
\hline
\end{tabular}

ERAS Enhanced Recovery After Surgery, LMWH low molecular weight heparin, DVT deep venous thrombosis, NSAIDS Non-Steroidal Anti-Inflammatory Drugs, PONV postoperative nausea and vomiting

(Mann-Whitney $\mathrm{U}$ test if the data distribution was skewed). For categorical data which were numeric, the Chi-squared test was used. A $p$-value $<0.05$ was considered statistically significant.

\section{Results}

Sixty-one patients were enrolled in this study, with 36 patients in the modified ERAS group and 25 patients in the SC group. There were no significant differences in terms of age, staging, body mass index, comorbidities and American Society of Anesthesiologists (ASA) score, operative procedures, and type of urinary diversion. The clinical characteristics of patients are shown in Table 3. There were significantly more male subjects in the study populations, reflecting that bladder cancer is more common in males compared to females.

The median LoS was decreased from 12.6 days in the $\mathrm{SC}$ groups to 9.3 days in the modified ERAS group $(P=0.032)$. In the modified ERAS group, there was also significant reduction in important postoperative milestones, including days to first solid diet ( $3.5 \pm 1.6 \mathrm{vs}$. $5.5 \pm 1.5, P=0.000)$, days to first defecation ( $4.8 \pm 2.4 \mathrm{vs}$. $7.2 \pm 2.4, P=0.001)$, days to first walking ( $4.7 \pm 2.2$ vs. $7.9 \pm 2.4, P=0.000)$, and days to drain removal $(3.9 \pm 1.3$ vs. $5.9 \pm 2.5 ; P=0.001$ ) (Table 4 ).

In this study, the overall complications were decreased in the modified ERAS group, but the result was not statistically significant $(P=0.282)$. According to the Clavien-Dindo classification, there were also no significant differences between both groups in terms of postoperative complication. However, high-grade (grade 3-5) complications were more common in modified ERAS group (Table 5).

The majority of patients in both groups required transfusion intra- or postoperatively, while in the modified
ERAS group, a lower transfusion rate was achieved (66.7\% for modified ERAS versus $88 \%$ for SC, $P=0.057$ ). In the SC group, the estimated intraoperative blood loss was higher, compared with the modified ERAS groups ( $1478 \pm 759.9$ vs. $751 \pm 579.9 ; P=0.000)$. The differences in postoperative intensive care monitoring are listed in Table 6.

Three patients in the SC group showed signs of peritonitis due to intestine anastomotic leakage, and 1 patient in the modified ERAS group had a high product drain due to end to side ureter anastomotic leakage before 7 days after surgery. All of these patients required emergency re-operation. Meanwhile, two other cases underwent re-operative debridement and surgical suturing due to wounds dehiscence.

There was also a decrease in re-admission rates within 30 days in the modified ERAS groups compared to the SC group, $8.3 \%$ and $16 \%$, respectively. All of the intra- and postoperative monitoring and complications are shown in Tables 5 and 6.

\section{Discussion}

Since its popularity in the 1990s [6], the enhanced recovery protocols have been increasingly applied in many clinical practices. This procedure is also widely applied in the field of urologic surgery, especially RC [11]. Several studies related to ERAS protocols in RC have shown good results in postoperative complications, functional recovery, and also LoS [12-14]. Application of several elements in the ERAS protocols, such as no preoperative bowel preparation and avoidance of opioid analgesia, results in early return of bowel function, reduced incidence of postoperative nausea and vomitus (PONV), and also reduced postoperative ileus $[10,15]$. 
Table 3 Clinical characteristics of the samples

\begin{tabular}{|c|c|c|c|}
\hline & $\begin{array}{l}\text { Modified } \\
\text { ERAS, } \\
N=36\end{array}$ & SC, $N=25$ & $P$ value \\
\hline Mean \pm SD age, years & $59.8 \pm 8.5$ & $59.9 \pm 9.6$ & 0.971 \\
\hline Gender, n (\%) & & & 0.037 \\
\hline Male & $27(75)$ & $24(96)$ & \\
\hline Female & $9(25)$ & $1(4)$ & \\
\hline Pathological finding, n (\%) & & & 0.300 \\
\hline Urothelial cell carcinoma & $32(88.8)$ & $19(76)$ & \\
\hline Squamous cell carcinoma & $3(8.8)$ & $3(12)$ & \\
\hline Adenocarcinoma & $1(2.7)$ & $3(12)$ & \\
\hline Staging, n (\%) & & & 0.615 \\
\hline $\begin{array}{l}\text { Organ-confine disease }(\leq \mathrm{pT} 2 \text {, } \\
\text { pN0) }\end{array}$ & $12(37.5)$ & $5(25)$ & \\
\hline $\begin{array}{l}\text { Extravesical disease ( } \geq \mathrm{pT} 3 \\
\text { or } \geq \mathrm{pN} 1 \text { ) }\end{array}$ & $18(56.2)$ & $13(65)$ & \\
\hline Metastatic disease & $2(6.2)$ & $2(10)$ & \\
\hline \multicolumn{4}{|l|}{ Comorbidity, n (\%) } \\
\hline Cardiovascular disease & $9(25)$ & $6(24)$ & 0.929 \\
\hline Diabetes mellitus & $1(2.7)$ & $2(8)$ & 0.562 \\
\hline Renal insufficiency & $1(2.7)$ & $9(36)$ & 0.383 \\
\hline Anemia & $17(47.2)$ & $6(24)$ & 0.066 \\
\hline Hypoalbuminemia & $12(33.3)$ & $6(24)$ & 0.432 \\
\hline Body Mass index, n (\%) & & & 0.061 \\
\hline Underweight & $20(55.5)$ & $21(84)$ & \\
\hline Norm weight & $15(41.6)$ & $4(16)$ & \\
\hline Overweight & $1(2.7)$ & 0 & \\
\hline ASA score, n (\%) & & & 0.549 \\
\hline 2 & $27(75)$ & $17(68)$ & \\
\hline 3 & $9(25)$ & $8(32)$ & \\
\hline Operative procedure, n (\%) & & & 0.500 \\
\hline Open surgery & $17(47.2)$ & $14(56)$ & \\
\hline Laparoscopy & $19(52.7)$ & $11(44)$ & \\
\hline Urinary diversion, n (\%) & & & 0.232 \\
\hline Ileal conduit & $16(44.4)$ & $15(60)$ & \\
\hline Transureterocutaneostomy & $20(55.5)$ & $10(40)$ & \\
\hline
\end{tabular}

All statistical analyses in this table used Chi-squared tests ERAS Enhanced Recovery After Surgery, SC standard of care

We modified the ERAS protocol in our center, and the main differences between the standard and modified ERAS protocols are in the administration of LMWH for thrombosis prophylaxis, carbohydrate loading before surgery, multimodal analgesia, postoperative oral intake, and use of perianastomotic and pelvic drainage (Table 2). There have been previous studies which eliminated some of the ERAS protocols in RC [16]. Interestingly, these studies showed consistent results where their protocol was effective in reducing LoS without any differences in complication and re-admission rates. This result was beneficial for the patients with reduced
Table 4 Postoperative milestones

\begin{tabular}{llrl}
\hline & $\begin{array}{l}\text { Modified } \\
\text { ERAS, } \\
\text { N=36 }\end{array}$ & SC, $\mathbf{N = 2 5}$ & P value \\
& $9.3 \pm 5.0$ & $12.6 \pm 6.7$ & 0.032 \\
Mean \pm SD length of stay, day & $3.9 \pm 1.3$ & $5.9 \pm 2.5$ & 0.001 \\
Mean \pm SD drain removal, day & & & \\
Mean \pm SD Functional recovery, & & & \\
day & $1.7 \pm 0.9$ & $3.0 \pm 0.2$ & 0.000 \\
First fluid diet & $3.5 \pm 1.6$ & $5.5 \pm 1.5$ & 0.000 \\
First solid diet & & & \\
Mean \pm SD Bowel activities, day & $1.8 \pm 1.2$ & $2.4 \pm 1.0$ & 0.074 \\
First flatulence & $4.8 \pm 2.4$ & $7.2 \pm 2.4$ & 0.001 \\
First defecation & & & \\
Mean \pm SD Mobilization, day & $1.6 \pm 0.9$ & $2.2 \pm 0.9$ & 0.042 \\
First sitting & $3.6 \pm 1.7$ & $6.2 \pm 2.6$ & 0.000 \\
First standing & $4.7 \pm 2.2$ & $7.9 \pm 2.4$ & 0.000 \\
First walking & & &
\end{tabular}

All statistical analyses in this table used independent t-test

ERAS Enhanced Recovery After Surgery, SC standard care, SD Standard Deviation

Table 5 Comparison of complication rates

\begin{tabular}{|c|c|c|c|}
\hline Complication rate & $\begin{array}{l}\text { Modified ERAS, } \\
N=36\end{array}$ & $\mathrm{SC}, N=25$ & $P$ value \\
\hline Overall, n (\%) & $11(30.5)$ & $11(44)$ & 0.282 \\
\hline $\begin{array}{l}\text { Clavien-Dindo classifica- } \\
\text { tion, n (\%) }\end{array}$ & & & 0.514 \\
\hline Grade 1-2 & $4(36.3)$ & $7(63.6)$ & \\
\hline Grade 3-4 & $5(45.4)$ & $3(27.2)$ & \\
\hline Grade 5 & $2(18.2)$ & $1(9.0)$ & \\
\hline
\end{tabular}

All statistical analyses in this table used independent t-test

ERAS Enhanced Recovery After Surgery, SC Standard care

LoS and also for the healthcare providers in terms of resources of care [12].

Additionally, postoperative recovery was also faster in the modified ERAS group, including bowel movement, mobilization, and functional recovery (Table 4). These findings indicate that patients in the modified ERAS groups experienced an early recovery and they could discharge earlier from the hospital. This is similar with a meta-analysis report by Tyson et al. [2] that found the ERAS protocol clearly enhanced postoperative recovery and LoS.

The advantages of the ERAS protocol are not only in LoS and early postoperative recovery. Several studies explained that the ERAS has a positive effect in reducing the incidence of complications $[12,16,17]$, such us postoperative ileus, the incidence decreased from $24 \%$ to $19.4 \%$ in our study. Several factors that can contribute to postoperative ileus including preoperative fasting, bowel preparation, opioid analgesia, use of a nasogastric 
Table 6 Intra- and postoperative monitoring

\begin{tabular}{llll}
\hline & Modified ERAS, $\mathbf{N = 3 6}$ & SC, $\boldsymbol{N}=\mathbf{2 5}$ & $\boldsymbol{P}$ value \\
\hline Median \pm IQR Intraoperative blood loss, $\mathrm{mL}$ & $500 \pm 400$ & $1500 \pm 1250$ & $0.000^{\mathrm{a}}$ \\
Requiring transfusion, $\mathrm{n}(\%)$ & $24(66.7)$ & $22(88)$ & $0.057^{\mathrm{b}}$ \\
Requiring intensive care, $\mathrm{n}(\%)$ & $9(25)$ & $3(12)$ & $0.328^{\mathrm{b}}$ \\
Adverse event, $\mathrm{n}(\%)$ & & & \\
Postoperative ileus & $7(19.4)$ & $2(24)$ & $0.669^{\mathrm{b}}$ \\
Re-operation within 30 days & $4(11.1)$ & $4(16)$ & $0.523^{\mathrm{b}}$ \\
Re-admission within 30 days & $3(8.3)$ & $1(4)$ & $0.299^{\mathrm{b}}$ \\
Mortality within 30 days & $2(5.5)$ & $0.636^{\mathrm{b}}$ \\
\hline
\end{tabular}

ERAS Enhanced Recovery After Surgery, SC standard care, IQR interquartile range

a Using Shapiro-Wilk and Mann-Whitney $U$ test analysis

${ }^{\mathrm{b}}$ Using Chi-square test analysis

tube (NGT), delayed mobilization, and postoperative diet restriction [12] have been eliminated in the modified ERAS protocol.

The higher rate of high-grade complications (grade 3-5) based on Clavien-Dindo classification in the modified ERAS group was a concern in this study. To our knowledge, there is no literature that demonstrates this finding. We assume that the difference of the sample size in both groups is the basis for this finding. Further investigation is still needed to validate these finding.

The significant difference in blood loss between both groups could be related with the surgical instrumentation and the surgeon's experience. In the previous series of RC procedures at our center, before the modified ERAS was applied, there was no adequate hemostasis control equipment such as a Harmonic and LigaSure machine. So, we still used the hemostasis technique with monopolar cauterization in the SC group which might affect the results.

We did not find any significant differences between the need for intensive care, re-admission, and mortality between both groups. These findings emphasize that the modified ERAS protocol has advantages in terms of early postoperative recovery, but the results were not significant in terms of morbidity and mortality. These findings were similar with previous several studies, which describe the benefits of the ERAS protocols in RC, including early functional recovery, early mobilization, bowel movement, and reduced LoS [18-20].

As far as we know, only a few studies have reported about ERAS for RC that include all of the ERAS protocol $[21,22]$, and there are no reports that mention the elements of the ERAS protocol that must be applied in RC surgery. This is confirmed by a meta-analysis study which found that a reduction in the elements of the ERAS protocol did not show inferior results compared to applying all of them [23]. Appropriately, there may be a need for a standardized protocol regarding the implementation of the ERAS protocols between any multidiscipline. In our center, there are many different points of view in terms of perioperative fasting, administration of anesthetic drugs, thrombosis prophylaxis, and prevention of nausea and vomiting. These differences warrant further study in the application of the ERAS protocols. We hope that in future, the standardized ERAS protocols can be applied to our center.

Remarkably, our study with several modified components of ERAS showed good results even without a full set of protocols. The reduction or modification of 4 or less components of the ERAS protocols also showed the same results with the application of all components [16, 23]. In the end, we noticed that the modified ERAS protocol gives a promising result. However, further studies are needed to assess the effect of individual ERAS components as separate variables.

Notably, the findings in this study have a good implication for the knowledge of perioperative care protocols. Our study has several limitations due to the retrospective design and potential for bias. However, the data were collected by only one person over a long period of time to avoid bias in data collection, so that the quality of data collection can be maintained. The study design was also a limitation in this study, since a randomized control trial was not used. Finally, the results support the recommendation that our modified ERAS protocol can be a clinical consideration in implementing the ERAS protocol in RC.

\section{Conclusions}

Adoption of modified ERAS protocol in perioperative care, particularly in RC, is supported by these data. The modified ERAS protocols dramatically reduced LoS and enhanced postoperative recovery. Furthermore, as compared to SC, the modified ERAS protocol had no significant impact on mortality and morbidity. More research is needed to validate and confirm the benefits of this study, 
such as ERAS enhances postoperative recovery, which may improve patients' quality of life also lowering healthcare costs and the efficacy of the modified ERAS protocols on a larger scale.

\section{Abbreviations}

ERAS: Enhanced Recovery After Surgery; SC: Standard of care; LoS: Length of stay; RC: Radical cystectomy; LMWH: Low molecular weight heparin; DVT: Deep venous thrombosis; NSAIDS: Non-Steroidal Anti-Inflammatory Drugs; PPI: Proton pump inhibitors; PONV: Postoperative nausea and vomiting; ASA: American Society of Anesthesiologists.

\section{Acknowledgements}

The authors acknowledge the medical research unit of Universitas Gadjah mada for supporting this study.

\section{Authors' contributions}

AZH and SAK involved in study concept and design. SAK and AZH involved in data acquisition. AZH, SAK and GAA took part in drafting of manuscript. SAK, GAA and AZH involved in critical revision of the manuscript. All authors have read and approved the manuscript.

\section{Funding}

Not applicable.

\section{Availability of data and materials}

The datasets used and/or analyses during the current study are available from the corresponding author on reasonable request.

\section{Declarations}

Ethics approval and consent to participate

This study was registered with the ethical clearances of Universitas Gadjah Mada, Medical and Health Research Ethics Committee (KE/FK/1388/EC/2020) and approved by the appropriate institutes' ethics committee. Consent to participate was not applicable as this was a retrospective chart review.

\section{Consent for publication}

Not applicable.

\section{Competing interests}

The authors declare that they have no competing interests.

\section{Author details}

${ }^{1}$ Division of Urology Oncology, Department of Surgery, Dr. Sardjito General Hospital, Universitas Gadjah Mada, Yogyakarta, Indonesia. 'Division of Urology, Department of Surgery, Dr. Sardjito General Hospital, Universitas Gadjah Mada, Yogyakarta, Indonesia.

\section{Received: 19 May 2021 Accepted: 1 August 2021}

Published online: 12 August 2021

\section{References}

1. Ibrahim H, Kotb S, Abd Allah A, Kassem A, Salem A, Abd ElHamid M et al (2020) Enhanced recovery protocol versus standard protocol for patients undergoing radical cystectomy: results of a prospective randomized study. African J Urol 26(1):2-5

2. Tyson MD, Chang S (2016) Enhanced recovery pathways versus standard care after cystectomy: a meta-analysis of the effect on perioperative outcomes. Eur Urol 70(6):995-1003

3. Brown JK, Singh K, Dumitru R, Chan E, Kim MP (2018) Benefits of ERAS programs and their application in cardiothoracic surgery. Methodist Debakey Cardiovasc J 14(2):77-88

4. Pramod S, Safriadi F, Hernowo B, Dwiyana R, Partogu B (2020) Modified enhanced recovery after surgery protocol versus nonenhanced recovery after surgery in radical cystectomy surgery (preliminary study). Urol Sci 31(4):177-182

5. Azhar RA, Bochner B, Catto J, Goh AC, Kelly J, Patel HD et al (2016) Enhanced recovery after urological surgery: a contemporary systematic review of outcomes, key elements, and research needs. Eur Urol 70(1):176-187

6. Melnyk M, Casey RG, Black P, Koupparis AJ (2011) Enhanced recovery after surgery (eras) protocols: time to change practice? J Can Urol Assoc 5(5):342-348

7. Krajewski W, Zdrojowy R (2020) Enhanced recovery after surgery (ERAS) in patients treated with radical cystectomy. AME Med J 5:3-3

8. Pruthi RS, Nielsen M, Smith A, Nix J, Schultz H, Wallen EM (2010) Fast tract program in patients undergoing radical cystectomy: results in 362 consecutive patients. J Am Coll Surg 210:93-99

9. Mukhtar S, Ayres BE, Issa R, Swinn MJ, Perry MJ (2013) Challenging boundaries: an enhanced recovery program for radical cystectomy. Ann R Coll Surg Engl 95:200-206

10. Arumainayagam N, McGrath J, Jefferson KP, Gillatt DA (2008) Introduction an enhanced recovery protocol for radical cystectomy. BJU Int 101:698-701

11. Vlad O, Catalin B, Mihai H, Adrian P, Manuela O, Gener I et al (2020) Enhanced recovery after surgery (ERAS) protocols in patients undergoing radical cystectomy with ileal urinary diversions: a randomized controlled trial. Medicine (Baltimore) 99(27):e20902

12. Dunkman WJ, Manning MW, Whittle J, Hunting J, Rampersaud EN, Inman BA et al (2019) Impact of an enhanced recovery pathway on length of stay and complications in elective radical cystectomy: a before and after cohort study. Perioper Med 8(1):1-10

13. Karl A, Buchner A, Becker A, Staehler M, Seitz M, Khoder W et al (2014) A new concept for early recovery after surgery for patients undergoing radical cystectomy for bladder cancer: results of a prospective randomized study. J Urol 191:335-340

14. Jensen BT, Petersen AK, Jensen JB, Laustsen S, Borre M (2015) Efficacy of a multiprofessional rehabilitation programme in radical cystectomy pathways: as prospective randomized controlled trial. Scand J Urol 49(2):133-141

15. Patel SY, Getting REG, Alford B et al (2018) Improved outcomes of Enhanced Recovery After Surgery (ERAS) protocol for radical cystectomy with addition of a multidisciplinary care process in a US comprehensive cancer care center. World J Surg 42:1-7

16. Liu B, Domes T, Jana K (2018) Evaluation of an enhanced recovery protocol on patients having radical cystectomy for bladder cancer. Can Urol Assosc J 12:421-426

17. Saar M, Ohlmann C, Siemer S et al (2012) Fast-track rehabilitation after robot-assisted laparoscopic cystectomy accelerates postoperative recovery. BJU Int 112(2):E99-E106

18. Giannarini G, Crestani A, Inferrera A et al (2014) Impact of fast-track versus conventional surgery in patients undergoing laparoscopic radical cystectomy and ileal conduit diversion: Chinese experience. Sci Rep 4:6820

19. Pang KH, Groves R, Venugopal S, Noon AP, Catto JW (2018) Prospective implementation of enhanced recovery after surgery protocols to radical cystectomy. Eur Urol 73:363-371

20. Smith A, Anders M, Auffenberg G, Daneshmand S, Elllimootil C, Fellows J et al (2018) New-optimizing outcomes in urologic surgery: postoperative. Am Urol Assoc 6:94

21. Patel HRH, Cerantola Y, Valerio M et al (2014) Enhanced recovery after surgery: are we ready, and can we afford not to implement these pathways for patients undergoing radical cystectomy? Eur Urol 65:263-266

22. Danna BJ, Wood EL, Baack Kukreja JE et al (2016) The future of enhanced recovery for radical cystectomy: current evidence, barriers to adoption, and the next steps. Urology 96:62-68

23. Nicholson A, Lowe MC, Parker J et al (2014) Systematic review and metaanalysis of enhanced recovery programmes in surgical patients. Br J Surg 101:172-188

\section{Publisher's Note}

Springer Nature remains neutral with regard to jurisdictional claims in published maps and institutional affiliations. 